ANADOLU, J. of AARI

ISSN: $1300-0225$ (Print)

E-ISSN: 2667-6087 (Online)

2021, 31 (1): 84-99

DOI: $10.18615 /$ anadolu.950101

\title{
Organik ve Konvansiyonel Tarım Koşullarında Yetiş̧tirilen Bazı Uçucu Yă̆ Bitkilerinin Kalite Özellikleri Üzerine Bir Ön Çalışma
}

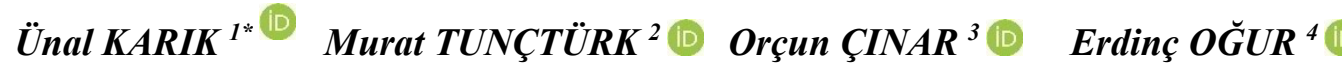 \\ ${ }^{1,4}$ Ege Tarımsal Araştırma Enstitüsü, İzmir/ TURKEY \\ ${ }^{2}$ Yüzüncü Yll Universitesi Ziraat Fakültesi, Tarla Bitkileri Bölümü, Van/TURKEY \\ ${ }^{3}$ Batı Akdeniz Tarımsal Araştırma Enstitüsü, Antalya/ TURKEY \\ ${ }^{1}$ https://orcid.org/0000-0001-6707-191X $\quad{ }^{2}$ https://orcid.org/0000-0002-7995-0599 \\ ${ }^{3}$ https://orcid.org/0000-0002-8356-384X $\quad{ }^{4}$ https://orcid.org/0000-0002-4496-2995 \\ *Corresponding author (Sorumlu yazar): unalkarik@gmail.com \\ Received (Geliş tarihi): 18.01.2021 Accepted (Kabul tarihi): 17.03.2021
}

\begin{abstract}
ÖZ: Bu çalı̧̧ma organik ve konvansiyonel tarım koşullarında yetiştirilen bazı tıbbi ve aromatik bitkilerin kalite özelliklerini belirlemek amacıyla yürütülmüşürr. Materyal olarak Anadolu adaçayı (Salvia fruticosa Mill.), İzmir kekiği (Origanum onites L.), lavandin (Lavandula $x$ intermedia Emeric ex Loisel.), lavander (Lavandula angustifolia Mill.), bahçe nanesi (Mentha spicata L.) ve tıbbi nane (Mentha $\boldsymbol{x}$ piperita L.) kullanılmıştır. Bitkiler tam çiçeklenme döneminde hasat edilmiş, inkübatörde kurutulmuş ve uçucu yağları su distilasyonu yöntemiyle çıkarılmıştır. Uçucu yağların kimyasal bileşimi GC/MS ile belirlenmiştir. Bitkilerdeki uçucu yağ oranları organik ve konvansiyonel tarım koşullarında türlere göre sırası ile Anadolu adaçayında \%2,8-,3,2, İzmir kekiğinde \%3,5-3,8, lavandinde \%5,4-6,3, lavanderde \%3,1-3,4, bahçe nanesinde $\% 1,7-2,2$ ve tıbbi nanede \%2,1-2,4 arasında değişim göstermiştir. Uçucu yağların ana bileșenleri ve oranları ise organik ve konvansiyonel tarım koşullarında türlere göre Anadolu adaçayında 1,8-sineol \%40,92-44,52, İzmir kekiğinde karvakrol $\% 43,84-48,47$, lavandinde linalol \%32,84-34,69, lavanderde linalil asetat \%33,03-36,28, bahçe nanesinde karvon \%53,6459,01 ve tıbbi nanede menthon \%40,86-45,32 arasında değişim göstermiştir. Sonuç olarak, organik tarım koşullarında incelenen tüm türlerin ис̧иси yă̆ oranlarının düștüğ̈̈ tespit edilmiştir. Bununla birlikte, organik ve konvansiyonel tarım koşullarında uçucu yağlarda bulunan ana bileşenlerin oranlarında önemli bir değişim meydana gelmemiştir.
\end{abstract}

Anahtar kelimeler: Salvia fruticosa Mill., Origanum onites L., Lavandula $x$ intermedia Emeric ex Loisel., Lavandula angustifolia Mill., Mentha spicata L., Mentha x piperita L., organic.

\section{The Preliminary Study on Quality Characteristics of Some Essential Oil Plants Grown Under Conventional and Organic Farming Conditions}

\footnotetext{
ABSTRACT: This study was carried out to determine the quality characteristics of some medicinal and aromatic plants grown under conventional and organic farming conditions. In the study, Anatolian sage (Salvia fruticosa Mill.), Turkish oregano (Origanum onites L.), lavandin (Lavandula $\boldsymbol{x}$ intermedia Emeric ex Loisel.), lavander (Lavandula angustifolia Mill.), spearmint (Mentha spicata L.) and pepermint (Mentha $\boldsymbol{x}$ piperita L.) species are used as a plant material. Plants were harvested in full bloom, dried in an oven, and their essential oils were extracted by water distillation. The chemical composition of the essential oils obtained was analyzed by GC/MS. Essential oil yield in organic and conventional farming conditions varied between, 2.8-3.2\% in Anatolian sage, 3.5-3.8\% in Turkish oregano, 5.4-6.3\% in
} 
Ü. KARIK, M. TUNCTÜRK, O. CINAR, E. OĞUR: ORGANIK VE KONVANSIYONEL TARIM KOSULLARINDA YETIŞTIRILEN BAZI UÇUCU YAĞ BITKILERININ KALITE ÖZELLIKLERİ ÜZERINE BİR ÖN ÇALIŞMA

lavandin, 3.1-3.4\%, in lavander, 1.7-2.2\% in spearmint and $2.1-2.4 \%$ in pepermint respectively. The main components and ratios of essential oils in samples obtained from organic and conventional farming; 1,8-cineole 40.92-44.52\% in Anatolian sage, 43.84-48.47\% carvacrol in Turkish oregano, linalool 32.84-34.69\% in lavandin, linalyl-acetate 33.03-36.28\% in lavander, carvone 53.64-59.01\% in spearmint and menthone 40.86-45.32\% in peppermint respectively. As a result, it was determined that the essential oil yields of all the species studied were decreased in organic farming conditions. However, no significant change occurred in the proportions of the main components in essential oils in organic and conventional farming conditions.

Keywords: Salvia fruticosa Mill., Origanum onites L., Lavandula x intermedia Emeric ex Loisel., Lavandula angustifolia Mill., Mentha spicata L., Mentha x piperita L., organic.

\section{GíRis}

Tıbbi ve aromatik bitkiler; gida, ilaç, kozmetik ve baharat gibi birçok kullanım amaçları olan ve insanlık tarihinin başlangıcından itibaren benzeri amaçlarla kullanıldıkları bilinen bitkilerdir. Söz konusu bitkilerin bir kısmı doğadan toplanırken bir kısmı da kültüre alınmış olup üretimi yapılmaktadır. Ancak tedavi amaçlı kullanılan bitkilerin önemli bir kısmı doğadan toplanmaktadır. Tibbi ve aromatik bitkilerin en çok göze çarpan ve araştırmaya konu olan özellikleri tedavi amaçlı kullanımlarıdır. Bitkilerle tedavi; geleneksel tedavi, tamamlayıcı tedavi, doğal tedavi gibi farklı isimlerle, gelişmemiş ülkeler başta olmak üzere dünyanın birçok ülkesinde kullanılmaktadır (Demirezer, 2010).

Organik kimya biliminin gelişmesi ile tıbbi bitkiler konusunda çok sayıda bilimsel çalışma yapılmış ve etkili kimyasal maddeler birkaç kısma ayrılmıştır. $\mathrm{Bu}$ maddeler glikozitler, alkaloitler, organik asitler, tanenler, vitaminler, karbonhidratlar, sabit ve uçucu yağlardır. Her bitkinin karakteristik kokusunu veren eterik yağların organik bileşenlerinin tamamının uçucu olduğu bulunmuştur. Bir uçucu yağın değeri, bileşimini meydana getiren kokulu bileşiklerin çeşidine, bunların bulunuş oranlarına, özelliklerine ve çeşitli sanayi dallarında kullanılma yerlerine bağlıdır. Farklı kullanım yerlerinde farklı özellikler aranmaktadır. Gıda sanayinde tuzlu suda çözünürlük özelliği, parfüm sanayinde alkolde çözünürlük özelliği gibi fiziksel özelliklerin yanı sıra gıda için toksik, parfüm için ise koku değeri, alerjik özelliği, istenen karışımlara uygunluğu gibi bazı kimyasal özellikleri eterik yağın kalitesi için önemli özelliklerdendir. Farklı türlerdeki yağların farklı kokulu olmasının sebebi bileşimlerindeki koku maddelerinin çeşit ve oranlarıdır. Bitkilerin gelişmesinde etkili olan çevre koşulları (iklim, ışık, toprak reaksiyonu, su, mineral maddeler), bitkinin yaşı, fizyolojik gelişme dönemi, hasat ve kurutma işlemleri gibi faktörler bitkideki etken maddelerin sentezlenmesine, elde edilen uçucu yağın miktarına ve kalitesine olumlu ya da olumsuz etkide bulunabilir. Hatta aynı yerde yetişen bitkilerde dahi bu farklılık bazen dikkati çekecek kadar fazladır (Yaşar, 2005).

Uçucu yağlardan elde edilen birçok madde, ilaç hammaddesi veya koku verici maddenin yarı sentez yoluyla elde edilişinde kullanılır. Örneğin kafur, pinenden; vanilin, öjenolden yarı sentetik olarak hazırlanmaktadır. Ayrıca uçucu yağların en önemli kullanım yeri doğal aromalardır. Birçok doğal aromanın sağlanmasında veya aromaların zenginleştirilmesinde kullanılmaktadır. Örneğin, karanfil yaprak yağından elde edilen öjenol ile doğal muz aroması sağlanır. Ayrıca uçucu yağlar dişçilik, ağız bakım ürünleri, parfümeri, boyacılık, madencilik ve gıdanın tüm alanlarında geniş ölçüde kullanılmaktadır (Çalıkoğlu ve ark., 2006).

Günümüzde ithalat ve ihracatı yapılan bitki türleri arasında ilk sırayı Lamiaceae familyası almaktadır. İçerik bakımından zengin aromatik tada, uçucu yağa ve hoş kokuya sahip olduğundan dolayı günümüzde önemini korumaktadır. Lamiaceae familyası dünya genelinde her bölgede yayılış gösterirken genel olarak Akdeniz bölgesinde ve Kuzey-Batı Asya bölgelerinde daha yaygın bir şekilde bulunmaktadır (Erdoğan, 2014). Genel olarak Akdeniz havzasında yayılış gösteren birçok türe sahip olan Lamiaceae familyası çok eski dönemlerden bu yana tıbbi bitki olarak kullanılmaktadır (Yaniv ve ark., 1982). Lamiaceae familyası dünya genelinde 250 cins ve 7000 tür 
içermektedir (Ulcay ve Şenel, 2018; Kahraman ve Doğan, 2010). Türkiye'de Lamiaceae familyasına ait 326 tanesi endemik olmak üzere 844 adet tür bulunmaktadır (Anonim, 2020a). Oldukça geniş bir familya olan Lamiaceae Türkiye'de de en büyük familyalar arasında yer almaktadır. Familya adaçayı (Salvia spp.), kekik (Origanum spp.) nane (Mentha spp.), reyhan (Ocimum spp.) ve lavanta (Lavandula spp.) gibi tıbbi ve aromatik bitkileri kapsamaktadır (Aktaş, 2001; Bağcı ve Koçak, 2008; Erdoğan, 2014; Karık, 2015).

Organik tarım genel itibariyle şu şekilde tanımlanabilir; "Ekolojik sistemdeki hatalı uygulamalara bağlı olarak bozulan doğal dengenin yeniden tesis edilmesine yönelik olarak insanlara ve doğaya zararı olmayan üretim sistemlerini içeren, genel olarak sentetik kimyasallar ve gübrelerin kullanılmasının yasaklanmasına ilaveten insanlara ve doğaya zararı olmayan ya da çok az zararı olan yeşil gübreleme, münavebe, toprağın korunmas1, bitki direncinin artırılması, parazit ve predatörlerle mücadeleyi öneren, tüm bu imkanların kapalı bir ortamda yapılmasını isteyen, üretimde miktar artışından ziyade ürün kalitesinin artırılmasını amaçlayan üretim şeklidir"(İlter ve Altındişli, 1996; İlter ve ark., 2012). Türkiye'de 2017 y1lında kekik, adaçayı ve nanede toplam 1010 ton, 2018 y1lında topam 293 ton ürün organik üretim sertifikası almıştır (Anonim, 2020b).

Ülkemizde tıbbi ve aromatik bitkiler sektöründe üretim alanları ve ürün çeşitliliği her geçen gün artmaktadır. Bunun ana nedeni olarak dünyada bu bitkilerden elde edilen ürünlere olan talebin artması gösterilebilir. Üretimde kullanılan girdiler, kayıt sistemi, çevreye olan etkiler ve izlenebilirlik gibi birçok farklı noktayı birlikte değerlendiren üretim sistemleri son zamanlarda önem kazanmıştır. Organik tarım uygulamaları bu parametreleri içeren, yetkili sertifika kuruluşları tarafından kanun ve yönetmeliklerle izlenip sertifikalandırılan üretim modelleridir. Tıbbi ve aromatik bitkilerin üretim alanı olarak öne çıkan Denizli ili Bekilli ilçesinde 2020 yılında yürütülen bu çalışmada, organik ve konvansiyonel olarak üretimi yapılan kekik, adaçayı, iki farklı lavanta türü, bahçe nanesi ve tıbbi nane türlerinden alınan bitki örneklerindeki uçucu yağ oranı ve bileşimi incelenmiştir. Böylece bu iki farklı üretim sisteminin bitkilerin kalite özelliklerine olan etkisi belirlenmiştir.

\section{MATERYAL ve METOT}

\section{Materyal}

Çalışmada materyal olarak Anadolu adaçayı (Salvia fruticosa Mill.), İzmir kekiği (Origanum onites L.), lavandin (Lavandula $x$ intermedia Emeric ex Loisel.), lavander (Lavandula angustifolia Mill.), bahçe nanesi (Mentha spicata L.) ve tıbbi nane (Menthaxpiperita L.) kullanılmıştır. Denzili ili, Bekilli ilçesi, Bükrüce köyünde belirtilen türlere ait 3 yıldır organik ve konvansiyonel üretim yapılan alanlardan, 2020 y1lı Temmuz ayında alınan bitki örnekleri ile çalışma yürütülmüştür. Çalışmada kullanılan organik bitkisel materyal, Likya Uluslararası Organik Ürünler Kontrol ve Sertifikasyon Hizmetleri Ltd. Şti. tarafindan Savaş UYAR adına 16.1137.012.BÜ sertifika numarası ile sertifikalandırılmıştır. Konvansiyonel bitki örnekleri, aynı bölgede ve aynı ekolojik koşullarda yetiştirilen bitkilerin yer aldığ $\breve{1}_{\text {üretim }}$ alanlarından 2020 yılı Temmuz ayında temin edilmiştir. Alınan bitkisel materyallerin tamamı çeşit vasfında olmayıp, populasyon niteliğindedir.

Çizelge 1'de Denizli ili Bekilli ilçesine ait uzun yıllar ortalamas1 ve 2020 yilına ait sicaklık ve yağış değerleri yer almaktadır. Çizelge 1 incelendiğinde bölgemin iklim özelliklerinin karasal iklim niteliği taşıdığı görülmektedir. Uzun y1llar ortalaması toplam yağış miktarı $302 \mathrm{~mm}$ olarak belirlenmiş, 2020 yılında toplam yağış $286.2 \mathrm{~mm}$ olarak gerçekleşmiştir. Sicaklık değerlerine baktığımızda uzun yıllar sıcaklık ortalamas1 $14.1{ }^{0} \mathrm{C}$ olurken, 2020 y1lı sicaklık ortalaması $14.6{ }^{0} \mathrm{C}$ olarak ölçülmüştür. Genel olarak incelendiğinde, çalışma yılına ait iklimsel verilerin, uzun y1llar ortalaması ile büyük oranda örtüştüğü anlaşılmaktadır.

Çalışmada kullanılan bitkisel materyallerin alındığı toprakların fiziksel ve kimyasal özelliklerine ilişkin yapılan analiz neticesinde elde edilen sinır değerler Çizelge 2'de verilmiştir. Toprakların bünye 
bakımından orta (50-55) seviyede olduğu, tuzluluk problemi içermediği $(0,1-0,3)$, kireç miktarının az $(0,3-0,6)$ ve organik madde miktarının orta $(2,2-2,7)$ düzeyde olduğu belirlenmiştir. Bu bilgiler 1şı̆̆ında, bitki örneklerinin alındığı tarlaların fiziksel ve kimyasal özellikleri bakımından bu bitkilerin tarımı için uygun olduğu söylenebilir.

\section{Metot}

Bitkilerin tam çiçeklenme döneminde, organik ve komvansiyonel üretim alanlarındaki üretici tarlasından, her tür için bir tarladan ve tarlanın farklı beş yerinden bitki örnekleri alınmıştır. Her türe ait alınan beş adet bitki örneği eşit miktarda karıştırılarak tek örnek haline getirilmiştir. Elde edilen tek örnekler $40 \mathrm{C}^{0}$ de 72 saat süre ile etüvde kurutulmuştur. Kurutulan bitkilerden alınan örneklerde uçucu yağ oranı ve uçucu yağın kimyasal bileşimi belirlenmiştir. Yapılan analizler ve bu analizlere ilişkin kullanılan yöntemler aşağıda ayrıntılı olarak verilmiştir.

Uçucu yağ oranı (\%): Kuru bitki örneklerinde uçucu yağ oranları Clevenger apareyi ile volümetrik olarak belirlenmiștir. $30 \mathrm{~g}$ drog $1000 \mathrm{ml}$ 'lik şilifli balona konmuş ve $300 \mathrm{ml}$ saf su ilave edilmiştir. Üzerine soğutucu taşıyan toplama büreti yerleștirilmiştir. Toplama büretine su konulmuştur. Sistem elektrikli isıtıcida 4 saat isitılarak distilasyona devam edilmiştir. Sürenin sonuna doğru soğutma suyu kapatılarak su buharının iyice yoğunlaşması beklenmiş ve derhal soğuk su akışı yeniden başlatılmıştır. $10 \mathrm{dk}$ sonra distilasyona son verilmiştir. Sistem kapatılıp, numune içindeki uçucu yağ miktarı hacim/ağırlık cinsinden hesaplanmıştır (Anonymous, 2010).

Çizelge 1. Bekilli ekolojik koşullarında deneme yılı ve uzun yıllar ortalama sıcaklık $\left({ }^{\circ} \mathrm{C}\right)$ ve toplam yağış (mm) değerleri (Anonim, 2021).

Table 1. Trial year and long term mean temperature $\left({ }^{\circ} \mathrm{C}\right)$ and total precipitation $(\mathrm{mm})$ values of Bekilli ecological conditions (Anonim, 2021).

\begin{tabular}{|c|c|c|c|c|}
\hline \multirow{2}{*}{$\begin{array}{l}\text { Aylar } \\
\text { Months }\end{array}$} & \multicolumn{2}{|c|}{$\begin{array}{c}\text { Sicaklik }{ }^{\circ} \mathrm{C} \\
\text { Temperature }{ }^{\circ} \mathrm{C}\end{array}$} & \multicolumn{2}{|c|}{$\begin{array}{c}\text { Yağış }(\mathrm{mm}) \\
\text { Precipitation }(\mathrm{mm})\end{array}$} \\
\hline & 2020 & $\begin{array}{l}\text { Uzun yillar } \\
\text { Long terms }\end{array}$ & 2020 & $\begin{array}{l}\text { Uzun yillar } \\
\text { Long terms }\end{array}$ \\
\hline Ocak (January) & 2,1 & 2,4 & 20,2 & 32,4 \\
\hline Şubat (February) & 5,2 & 4,3 & 60,3 & 77,6 \\
\hline Mart (March) & 9,4 & 5,2 & 42,4 & 32,5 \\
\hline Nisan (April) & 10,7 & 10,3 & 12,8 & 12,3 \\
\hline Mayıs (May) & 13,6 & 15,3 & 21,5 & 22,7 \\
\hline Haziran (Jun) & 15,8 & 20,6 & 10,7 & 12,6 \\
\hline Temmuz (July) & 27,3 & 23,7 & 0,0 & 0,7 \\
\hline Ağustos (August) & 27,1 & 25,4 & 7,2 & 6,9 \\
\hline Eylül (September) & 26,5 & 23,2 & 6,3 & 7,2 \\
\hline Ekim (October) & 19,7 & 19,8 & 7,6 & 8,8 \\
\hline Kasım (November) & 12,4 & 13,3 & 6,4 & 7,5 \\
\hline Aralık (December) & 6,1 & 5,2 & 90,8 & 80,8 \\
\hline Ortalama (Average) & 14,6 & 14,1 & 286,2 & 302,0 \\
\hline
\end{tabular}

Çizelge 2. Toprak örneklerinin bazı fiziksel ve kimyasal özellikleri.

Table 2. Some physical and chemical properties of soil samples.

\begin{tabular}{|c|c|c|c|c|c|c|c|}
\hline $\begin{array}{l}\text { Derinlik } \\
\text { Depth }\end{array}$ & $\begin{array}{l}\text { Tekstür } \\
\text { Texture }\end{array}$ & $\begin{array}{c}\text { EC25 } \\
(1: 2.5) \\
\text { Salinity }\end{array}$ & $\begin{array}{c}\mathrm{pH}(1: 2.5) \\
\mathrm{pH}\end{array}$ & $\begin{array}{c}\text { Kireç }(\%) \\
\text { Lime }\end{array}$ & $\begin{array}{c}\text { Organik madde } \\
\text { Organic matter } \\
(\%)\end{array}$ & $\begin{array}{c}\text { Alınabilir } \mathrm{P}_{2} \mathrm{O}_{5} \\
\text { Available } \mathrm{P}_{2} \mathrm{O}_{5} \\
(\mathrm{ppm})\end{array}$ & $\begin{array}{c}\text { Değişebilir } \mathrm{K}_{2} \mathrm{O} \\
\text { Variable } \mathrm{K}_{2} \mathrm{O} \\
(\mathrm{ppm})\end{array}$ \\
\hline $0-30$ & $50-55$ & $0,1-0,3$ & $7,2-7,6$ & $0,3-0,6$ & $2,2-2,7$ & $32-44$ & $248-264$ \\
\hline & $\begin{array}{l}\text { Killi tın } \\
\text { Clay loam }\end{array}$ & $\begin{array}{c}\mathrm{Az} \\
\mathrm{Few}\end{array}$ & $\begin{array}{c}\text { Hafif alkali } \\
\text { Slightly alkaline }\end{array}$ & $\begin{array}{l}\text { Eseri } \\
\text { Trace }\end{array}$ & $\begin{array}{l}\text { Orta } \\
\text { Middle }\end{array}$ & $\begin{array}{c}\text { Yeterli } \\
\text { Sufficient }\end{array}$ & $\begin{array}{c}\text { Yeterli } \\
\text { Sufficient }\end{array}$ \\
\hline
\end{tabular}


Uçucu yağın bileşimi (\%): Uçucu yağlarda bulunan kimyasal bileşenlerin adları ve oranları GC ve GC/MS ile belirlenmiştir. Öncelikle uçucu yağ örnekleri analiz edilmek üzere 1:50 oranında hekzan ile seyreltme işlemine tabi tutulmuştur.

\section{Gaz Kromatografisi (GC) analiz koşulları}

Sistem: Agilent 6890N GC GC analiz koşulları; eş zamanlı olarak GC/MS sistemindeki madde çıkış zamanları ile aynı olacak şekilde ayarlanmıştır (FID $300^{\circ} \mathrm{C}$ ). $\mathrm{Bu}$ amaçla kapiler kolon (HP Innowax Capillary; $60.0 \mathrm{~m} \times 0.25 \mathrm{~mm} \times 0.25 \mu \mathrm{m}$ ) kullanılmıştır.

\section{Gaz Kromatografisi/Kütle Spektrometrisi (GC/} MS) analiz koşulları

Sistem: Agilent 5975 GC-MSD sistemi

Kolon: HP-Innowax Silika kapiler (60 m x 0.25 $\mathrm{mm} \varnothing, 0.25 \mathrm{~m}$ film kalınlı ğı)

Sicaklık Programı: $60^{\circ} \mathrm{C}$ de 10 dak $/ / 4^{\circ} \mathrm{C} / \mathrm{dak}$ artışla $220^{\circ} \mathrm{C}$ ye $/ / 220^{\circ} \mathrm{C}$ de 10 dak $/ / 1^{\circ} \mathrm{C} /$ dak artışla $240^{\circ} \mathrm{C}$

Enjektor: $250^{\circ} \mathrm{C}$

Taşıyııı Gaz: Helyum ( $0,8 \mathrm{ml} / \mathrm{dak})$

Split oranı: Splitless

Elektron enerjisi: $70 \mathrm{eV}$

Kütle Aralığı: m/z 35-450 olacak şekilde cihaz şartlandırılmıştır.
Örneklerin uçucu yağın bileşenlerinin teşhisinde Başer Uçucu Yağ Bileşenleri Kütüphanesi, Wiley ve Adams-LIBR (TP) Kütüphane Tarama Yazılımları kullanılmıştır. Elde edilen bileşenlerin yüzdeleri FID dedektör kullanılarak, tanımlaması ise MS dedektör kullanılarak yapılmıştır. Uçucu yağ bileşenlerinin alıkonma indisleri (RI), her bir bileşenin alıkonma zamanı ve C8-C22 karbon serili n-alkan serisinin aynı analiz koşulları için belirlenen alıkonma zamanları dikkate alınarak hesaplanmıștır.

\section{BULGULAR ve TARTIŞMA}

\section{Uçucu Yağ Oranı (\%)}

Çalışmada kullanılan türlerin uçucu yağ oranları Çizelge 3'te verilmiştir. Türlere göre baktığımızda, organik üretimde uçucu yağ oranı Anadolu adaçayında \%2,8, İzmir kekiğinde \%3,5, lavandinde $\% 5,4$, lavanderde $\% 3,1$, bahçe nanesinde $\% 1,7$ ve tıbbi nanede $\% 2,1$ olarak belirlenmiştir. Konvansiyonel üretimde ise uçucu yağ oranı Anadolu adaçayında \%3,2, İzmir kekiğinde \%3,8, lavandinde $\% 6,3$, lavanderde $\% 3,4$, bahçe nanesinde $\% 2,2$ ve tıbbi nanede \%2,4 olarak bulunmuştur. Çizelge 3 incelendiğinde, genel olarak organik üretimden elde edilen uçucu yağ oranı değerlerinin, konvansiyonel üretimden elde edilenlere göre daha düşük olduğu görülmektedir.

Çizelge 3. Çalışmada kullanılan türlerin uçucu yağ oranı (\%).

Table 3. Essential oil ratio of species used in the study (\%).

\begin{tabular}{|c|c|c|c|}
\hline $\begin{array}{l}\text { Türkçe adı } \\
\text { Turkish name }\end{array}$ & $\begin{array}{l}\text { Latince adı } \\
\text { Latin name }\end{array}$ & $\begin{array}{l}\text { Organik uçucu yağ oranı (\%) } \\
\text { Organic essential oil ratio (\%) }\end{array}$ & $\begin{array}{l}\text { Konvansiyonel uçucu yağ oranı (\%) } \\
\text { Conventional essential oil ratio (\%) }\end{array}$ \\
\hline $\begin{array}{l}\text { Anadolu adaçay1 } \\
\text { Anatolian sage }\end{array}$ & Salvia fruticosa Mill. & 2,8 & 3,2 \\
\hline $\begin{array}{l}\text { İzmir kekiği } \\
\text { Turkish oregano }\end{array}$ & Origanum onites L. & 3,5 & 3,8 \\
\hline $\begin{array}{l}\text { Lavandin } \\
\text { Lavandin }\end{array}$ & $\begin{array}{l}\text { Lavandula } x \text { intermedia } \\
\text { Emeric ex Loisel. }\end{array}$ & 5,4 & 6,3 \\
\hline $\begin{array}{l}\text { Lavander } \\
\text { Lavander }\end{array}$ & Lavandula angustifolia $\mathrm{L}$. & 3,1 & 3,4 \\
\hline $\begin{array}{l}\text { Bahçe nanesi } \\
\text { Spearmint }\end{array}$ & Mentha spicata L. & 1,7 & 2,2 \\
\hline $\begin{array}{l}\text { Tibbi nane } \\
\text { Peppermint }\end{array}$ & Mentha $x$ piperita $\mathrm{L}$. & 2,1 & 2,4 \\
\hline
\end{tabular}




\section{Anadolu adaçayı (Salvia fruticosa Mill.)}

Anadolu adaçayında (Salvia fruticosa Mill.) değişik araştırıcılar tarafından farklı yerlerde yapılan çalışmalarda; Kalafatcılar (1996) Batı Anadolu Bölgesinin değişik yörelerinden topladığı Salvia fruticosa Mill.'da uçucu yağ oranını \%1,55,15, Bayram ve ark. (1999) Antalya ve Muğla florasindan toplanan populasyonlarda 1 . y1 \%3,555,28, 2. y11 \%3,47-5,40 arasinda, Bayram (2001) Bornova ekolojik koşullarında oluşturduğu klonlarında ortalama \%3,68, Mossi ve ark. (2011) Brezilya'da yürüttükleri çalışmada $\% 0,98$, Putievsky ve ark. (1986) İsrail florasında yaptıkları çalışmada \%1,4-3,8 arasında, Karoussou ve Kokkini (1997) Girit Adası'ndaki populasyonlarda $\% 1 \% 5,5$ arasinda, Baydar ve ark. (1999) Isparta Bölgesinde \%1,95, Aşkun ve ark. (2010) Marmara Adasında \%2,3, Kocabaş ve ark. (2010) Antalya'da yürüttüğü çalışmada \%2,9 Çiçek ve ark. (2011) İzmir Menemen koşullarında \%1,14 ile \%4,58 arasında, Karayel ve Akçura (2016) üç farklı lokasyonda (Kütahya, Balıkesir, Çanakkale) yetiştirilen Salvia fruticosa Mill. bitkisinin uçucu yağ oranını sırasıyla $\% 1,93, \% 2,72$ ve $\% 4,10$, Leontaritou ve ark. (2020) Yunanistan'da 10 farklı bölgeden topladıkları Salvia fruticosa Mill. populasyonlarının uçucu yağ oranının \%2,17 ile $\% 4,20$ arasında değişim gösterdiğini belirlemiştir. Seidler-Lozykowska ve ark. (2014) yaptıkları çalışmada, organik olarak yetişririlen Salvia officinalis L.' de uçucu yağ oranını \%1,2 olarak belirlemişlerdir. $\mathrm{Bu}$ çalışmaların tamamı değerlendirildiğinde, Salvia fruticosa Mill. uçucu yağ oranının \%1,145,40 arasında değiştiği görülmektedir. Yaptığımız çalışmada elde ettiğimiz organik uygulamada $\% 2,8$ ve konvansiyonel uygulamada \%3,2 uçucu yă değerleri, daha önceki çalışmalardan elde edilen değerlerin büyük bir bölümü ile benzerlik göstermektedir.

\section{İzmir kekiği (Origanum onites L.)}

İzmir kekiğinde (Origanum onites L.) uçucu yağ oranları bakımından diğer araştırıcıların elde ettiği değerler incelendiğinde; Kırman (1993), geliştirilmiş Origanum onites L. hatlarında drog yaprak uçucu yağ oranlarının \%1,66-3,00 arasında değiştiğini,
Ceylan ve ark. (1994) ortalama \%2,92 olduğunu, Otan ve ark. (1994) \%0,12-5,54 arasında değişim gösterdiğini bildirmişlerdir. Bayram (1995) Bornova ekolojik koşullarında ortalama \%2,0-2,81 arasında olduğunu belirtmiştir. Arabacı (1995) yapmış olduğu araştırmada, uçucu yağ oranlarının \%2,02-2,33 arasında, Özsoy (1995) Muğla yöresinden toplanan Origanum onites L. populasyonlarından yetiştirilen tek bitkilerde \%2,48 olarak tespit etmişlerdir. Kıtıkı ve ark. (1997), Batı Anadolu İzmir kekiği populasyonlarında en yüksek uçucu yağ oranını \%5,50 olarak bildirmişlerdir. Ceylan ve ark. (1999) yaptıkları araştırmada uçucu yağ oranlarının iki yıllık ortalamasının \%2,61-5,12 arasında değiştiğini saptamışlardır. Bayram ve ark. (1999) İzmir kekiğinde farklı biçim şekli ve biçim yüksekliğinde uçucu yağ oranını ilk yıl \%2,363,11 , ikinci yıl ise \%1,74-2,45 arasında değiştiğini tespit etmişlerdir. Baydar (2002), Isparta koşullarında kültüre alınan Origanum onites L. drog yapraklarında uçucu yağ oranını ortalama \%3,55 olarak bulmuştur. Avc1 ve Bayram (2013), İzmir'de farklı ekolojik koşullarda yetiştirdikleri Origanum onites L. klonlarının uçucu yağ miktarını \%2,77 ile \%4,20 aralığında, Stefanaki ve ark. (2016) yaptıkları çalışmada Yunanistan'dan 42 farklı lokasyondan topladıkları Origanum onites L. örneklerinin uçucu yağ oranının \%3,0 ile \% 7,0 arasında, Economou ve ark. (2011) Yunanistan'da 7 farklı lokasyondan topladıkları Origanum onites L. örneklerinin uçucu yă oranını \%3,0-4,3 aralığında bulmuşlardır. Kosakowska ve Bqczek (2019) yaptıkları çalışmada, organik olarak yetiştirilen Origanum vulgare subsp. hirtum'da uçucu yağ oranını \%5,8 olarak belirlemişlerdir. İzmir kekiğinde (Origanum onites L.) organik ve konvansiyonel çalışmalardan elde edilen $\% 3,5$ ve $\% 3,8$ uçucu yağ değerleri, önceki çalışmalardaki sınır değerler olan \%0,12-7,0 değerleri arasında yer almakta ve çalışmaların elde edilen değerlerin büyük bölümü ile örtüşmektedir.

\section{Lavanta (Lavandula $x$ intermedia Emeric ex Loisel, Lavandula angustifolia Mill.)}

Lavanta türleri hakkında yürütülen çalışmalarda; Ceylan ve ark. (1988) Lavandula officinalis L.'in uçucu yağ oranının \%1,26-3,14, arasında değiştiğini, 
Renaud ve ark. (2001) lavandin kuru çiçek tomurcuklarında $\% 7,1-9,9$ ve lavander çeşitlerinin kuru çiçek tomurcuklarında ise \%2,8-5,0 arasında uçucu yağ içerdiğini bildirmişlerdir. Baydar (2007) Isparta'da yetiştirilen Super lavandin çeşidinin uçucu yağ oranını saplı taze çiçeklerinde \%1,0-1,5 arasında, sapsız kuru çiçeklerinde \%5-6 arasında değiştiğini, Kara ve Baydar (2011) lavantanın (Lavandula $x$ intermedia Emeric ex Loisel. var. Super) uçucu yağ oranını kuru sapsız çiçekte \%7,50-8,60 arasında, Atalay (2008) Lavandula angustifolia Mill.'nın drog çiçeğinde uçucu yağ oranını \%2,1-2,6, aynı lavanta türünde Arabacı ve Bayram (2005) uçucu yağ oranının \%1,54-2,34, Kara (2011) \%2,1-9,62 arasında değiştiğini bildirmişlerdir. Seidler-Lozykowska ve ark. (2014) yaptıkları çalışmada organik olarak yetiştirilen Lavandula angustifolia Mill. bitkisinde uçucu yağ oranını \%1,78-2,04 arasında belirlemişlerdir. Detar ve ark. (2020) yaptıkları çalışmada Macaristan'da yetiştirilen iki Lavandula $x$ intermedia Emeric ex Loisel. çeşidinin uçucu yă oranlarını \%4,4-9,5 arasında, Sönmez ve Okkaoğlu (2019) yaptıkları çalışmada Adana'da yetiştirilen Lavandula angustifolia Mill. bitkisinin uçucu yağ oranını $\% 2,65$ ile \%4,45 arasında, Moussii ve ark. (2020) yaptıkları çalışmada Lavandula angustifolia Mill. bitkisinin uçucu yağ oranını \%2,32, Blazekovic ve ark. (2018) Hırvatistan'da yetiştirilen Lavandula x intermedia Emeric ex Loisel. çeşidinin uçucu yağ oranını \%3,3 olarak belirlemişlerdir. Yaptığımız çalışmada lavandin (Lavandula $x$ intermedia Emeric ex Loisel.)'de uçucu yağ oranı organik ve konvansiyonel üretimde \%5,4-6,3 arasında bulunmuş olup, önceki çalışmalardan elde edilen \%3,3-9,9 değerleri ile uyumludur. Lavander (Lavandula angustifolia Mill.)'den organik ve konvansiyonel uçucu yă̆ oranı değerleri \%3,1-3,4 arasında belirlenmiş olup, önceki çalışmalardan elde edilen \%1,26-5 değerleri arasında yer almaktadır.

\section{Nane (Mentha spicata L., Mentha $\mathbf{x}$ piperita L.)}

Daha önce farklı bölgelerde Mentha spicata L. türleri ile yapılan çalışmalarda; Telci (2001), Tokat koşullarında Mentha spicata L. türünde $\% 0,80$ 3,76 arasında, Sülü (2010), Tokat-Kazova ekolojik koşullarında ilk biçimde $\% 0,82-2,37$, ikinci biçimde \%1,37-3,19 arasında, Özgüven ve Kırıcı (1999), Adana ve Pozantı lokasyonlarında \%1,57-6,29 arasında, Büyükbayraktar (2014), Konya'da yapmış olduğu çalışmada Mentha spicata L. da \%1,4-2,0 arasında, Kedia ve ark. (2014) yaptıkları araştırmada Hindistan'dan topladıkları Mentha spicata L. türünün uçucu yağ oranını $\% 0,6$, Telci ve ark. (2010) 4 farklı lokasyonda (Aydın, Bursa, İzmir ve Tokat) yetiştirdikleri. Mentha spicata L. bitkilerinin uçucu yağ oranlarını \%2,41 ile \%2,74 arasında belirlemişlerdir. Özgüven ve Kırıcı (1999) 5 farklı Mentha x piperita L. çeşidinin Adana ve Mersin koşullarında uçucu yağ oranlarının \%2,06 ile \%6,57 arasında değişim gösterdiğini, Rajkumar ve ark. (2019) yaptıkları çalışmada Mentha $x$ piperita L bitkisinin uçucu yağ oranını \%1,79 olarak belirlemişlerdir. Esetlili ve ark. (2015) organik olarak yetiştirilen Mentha x piperita L. uçucu yağının oranını \%3,7 olarak bulmuşlardır. Zhao ve ark. (2013) Çin'de 8 farklı lokasyondan topladıkları Mentha spicata türünde uçucu yağ oranlarının \%0,5-0,8 arasında değişim gösterdiğini bulmuşlardır. Ayran ve ark. (2018) yaptıkları çalışmada Mentha x piperita L uçucu yağ oranını \%3,2 olarak belirlemişlerdir. Çalışmamızda Mentha spicata L. türünde organik üretimde $\% 1,7$, konvansiyonel üretimde $\% 2,2$ uçucu yağ oranı elde edilmiş olup, önceki çalışmalardan elde edilen sınır değerler olan \%0,8-6,29 arasında yer almaktadır. Mentha $\mathrm{x}$ piperita L. türünden organik uygulamada $\% 2,1$, konvansiyonel uygulamada \%2,4 uçucu yağ oranı elde edilmiştir. Bu değer diğer çalışmalardan alınan \%0,5-6,57 değerlerinin arasındadır. Bahçe nanesinde (Mentha spicata L.) uçucu yağ oranı bitkinin genetik yapısına (Ceylan 1987; Özgüven ve Kırıc1 1999; Tuğay ve ark. 2000), ilkim koşullarına (Özgüven ve Kırıcı 1999) göre değişim göstermektedir.

Bitkilerde sekonder maddelerin oluşumu, genetik yapısı ile birlikte çevre faktörlerine bağlı olarak ortaya çıkmaktadır. Bitkinin yetiştiği çevredeki iklim faktörleri ile birlikte edafik faktörler de büyük rol oynamaktadır (Franz, 1983; Palevitch, 1987). 


\section{Uçucu Yă̆ Bileşenleri (\%)}

\section{Anadolu adaçayı (Salvia fruticosa Mill.)}

Çizelge 4'te Anadolu adaçayı (Salvia fruticosa Mill.) uçucu yağ bileşenlerine baktığımızda, toplam 21 bileşenin tanımlandığı görülmektedir. Konvansiyonel ve organik üretimden gelen yağların, içerik olarak aralarında büyük farkların olmadığı anlaşılmaktadır. Uçucu yağın ana bileșeni olan 1,8cineole konvansiyonel ve organik uygulamalarda sirası ile \%44,52 ve \%40,92 oranında ölçülmüştür. Diğer bir bileşen olan camphor ise \%12,65-17,53 arasında belirlenmiştir.

Salvia fruticosa Mill. ile ilgili daha önce yapılan çalışmalarda; Karayel ve Akçura (2016) üç farklı lokasyonda (Kütahya, Balıkesir, Çanakkale) yetiştirilen Salvia fruticosa Mill. bitkisinin uçucu yağında 1,8-cineole en yüksek \%56,05 oranı ile Kütahya lokasyonunda elde edilmiş, Leontaritou ve ark. (2020) yaptıkları çalışmada Yunanistan'da
10 farklı bölgeden topladıkları Salvia fruticosa Mill. populasyonlarında uçucu yağın ana bileşeni olan 1,8- cineole \%27,78-46,65 arasında değişim göstermiş, Skoula ve ark. (2000) Yunanistan'da 3 farklı yerde yetiştirdikleri Salvia fruticosa Mill. örneklerinde ana bileşen olarak 1,8-cineole \%48,06-59,27 aralığında tespit edilmiş, Delamare ve ark. (2007) yaptıkları çalışmada Güney Brezilya'da yetiştirilen Salvia fruticosa Mill. bitkisinde uçucu yağın ana bileşeni olarak 1,8cineole $(\% 15,7)$ tespit etmişlerdir. SeidlerLozykowska ve ark. (2014) yaptıkları çalışmada, organik olarak yetişririlen Salvia officinalis L.'de uçucu yağ oranını Seidler-Lozykowska ve ark. (2014) yaptıkları çalışmada, organik olarak yetişririlen Salvia officinalis L.'de uçucu yağda 1,8-cineole oranını \%15,8 olarak belirlemişlerdir. Yapılan çalışmalardan elde edilen sonuçlar, elde ettiğimiz sonuçlar ile uyumludur.

Çizelge 4. Anadolu adaçayı (Salvia fruticosa Mill.) uçucu yağ bileşenleri (\%)

Table 4. Essential oil composition of Anatolian sage (Salvia fruticosa Mill.)

\begin{tabular}{ccccc}
\hline RI** & R.T.* & $\begin{array}{c}\text { Bileşen } \\
\text { Compounds }\end{array}$ & $\begin{array}{c}\text { Konvansiyonel (\%) } \\
\text { Conventional (\%) }\end{array}$ & $\begin{array}{c}\text { Organik (\%) } \\
\text { Organic (\%) }\end{array}$ \\
\hline 1021 & 10,528 & alpha-pinene & 6,42 & 5,93 \\
1024 & 10,641 & alpha-thujene & 0,46 & 1,43 \\
1063 & 12,075 & camphene & 6,98 & 5,67 \\
1107 & 13,686 & beta-pinene & 5,65 & 5,05 \\
1160 & 16,017 & myrcene & 2,31 & 2,22 \\
1198 & 17,648 & limonene & 2,14 & 2,42 \\
$\mathbf{1 2 1 0}$ & $\mathbf{1 8 , 1 6 5}$ & $\mathbf{1 , 8 - c i n e o l e ~}$ & $\mathbf{4 4 , 5 2}$ & $\mathbf{4 0 , 9 2}$ \\
1243 & 19,597 & gamma-terpinene & 0,36 & 0,29 \\
1268 & 20,669 & cymene & 1,45 & 1,29 \\
1427 & 26,884 & alpha-thujone & 3,22 & 3,33 \\
1447 & 27,559 & beta-thujone & 2,84 & 2,55 \\
1524 & 30,196 & camphor & 12,65 & 17,53 \\
1541 & 30,724 & linalool & 0,23 & 0,31 \\
1553 & 31,143 & linalyl acetate & 0,33 & 0,32 \\
1583 & 32,053 & bornyl acetate & 0,86 & 0,91 \\
1603 & 32,687 & beta-caryophyllene & 3,45 & 3,41 \\
1651 & 34,125 & sabinyl acetate & 0,26 & 0,20 \\
1678 & 34,915 & alpha-humulene & 1,01 & 0,83 \\
1699 & 35,531 & alpha-terpineol & 2,82 & 2,78 \\
1701 & 35,599 & borneol & 1,36 & 1,34 \\
2008 & 43,651 & caryophyllene oxide & 0,23 & 0,22 \\
\hline Toplam/Total & \multicolumn{5}{c}{} & 99,55 & 98,95 \\
\hline
\end{tabular}

RT*: Retantion Time (Alıkonma Zamanı); RI** Retantion Indice (Alıkonma İndisi). 


\section{İzmir kekiği (Origanum onites L.)}

İzmir kekiği (Origanum onites L.) uçucu yağının bileşenleri Çizelge 5'te görülmektedir. Kekik olarak adlandırılan bitkilerin uçucu yağında esas olarak carvacrol ve/veya thymol adlı bileşenler yer almaktadır. Yaptığımız çalışmada uçucu yağların ana bileşeni olarak carvacrol tanımlanmıştır. Carvacrol oranı konvansiyonel üretimde $\% 48,47$ olarak belirlenirken, organik üretimde $\% 43,84$ olarak ölçülmüştür. Kekikte diğer önemli bilşen olan thymol ise \%11,79-10,08 arasında belirlenmiştir.

Özkan ve Erdoğan (2011) yaptıkları çalışmada Antalya'dan toplanan Origanum onites bitkisinin uçucu yağında \%24,52 carvacrol olduğunu, Avc1 ve Bayram (2013) İzmir'de farklı ekolojik koşullarda yetiştirdikleri Origanum onites L. klonlarında uçucu yağın ana bileşeni olarak carvacrolün \%83,86-93,69 aralığında değişim gösterdiğini, Baydar (2002) Isparta koşullarında yetiştirdiği Origanum onites L. bitkisinin uçucu yağ ana bileşeni olan carvacrolün \%54,81-72,43 arasında olduğunu, Stefanaki ve ark. (2016) yaptıkları çalışmada Yunanistan'dan 42 farklı lokasyondan topladıkları Origanum onites L. örneklerinde uçucu yağın ana bileșeni olan carvacrolü \%69,0-92,6 aralığında tespit ettiklerini, Economou ve ark. (2011) Yunanistan'da 7 farklı lokasyondan topladıkları Origanum onites L. örneklerinin uçucu yağ ana bileşeni olan carvacrolün $\% 72,25$ ile \%89,22 arasında değiştiğini, Bostancıoğlu ve ark. (2012) yaptıkları araştırmada Batı Anadolu bölgesinden topladıkları Origanum onites L. yağının ana bileşeni olarak carvacrol $(\% 64,3)$ olarak tespit ettiklerini bildirmişlerdir. Kosakowska ve Bqczek (2019) yaptıkları çalışmada, organik olarak yetiştirilen Origanum vulgare subsp. hirtum' da carvacrol oranın $\% 73,85$ olarak belirlemişlerdir. Yaptığımız çalışmadan elde ettiğimiz carvacrol değerleri $(\% 43,84-48,47)$ yukarıda verilen çalışmalardan elde edilen değerlerin biraz altındadır. Bitkilerde sekonder maddelerin oluşumu, genetik yapısı ile birlikte çevre faktörlerine bağlı olarak ortaya çıkmaktadır. Bitkinin yetiştiği çevredeki iklim faktörleri ile birlikte edafik faktörler de büyük rol oynamaktadır (Franz, 1983; Palevitch, 1987).

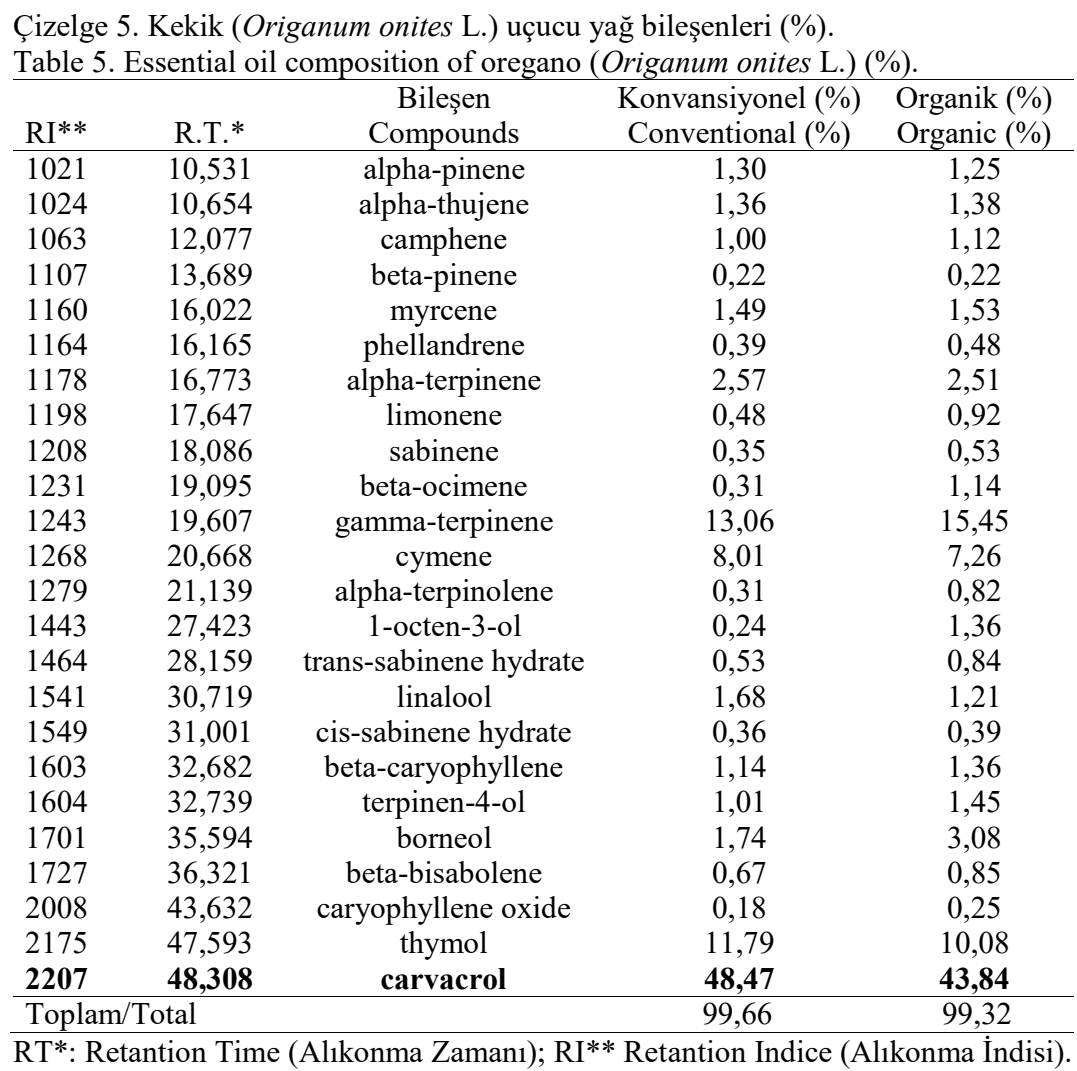




\section{Lavanta (Lavandula $x$ intermedia Emeric ex Loisel., Lavandula angistifolia Mill.)}

Yaptığımız çalışmada Lavandula $x$ intermedia Emeric ex Loisel. ve Lavandula angistifolia Mill. türlerinden elde edilen uçucu yağların kimyasal bileşimi Çizelge 6 ve Çizelge 7'de görülmektedir. Lavandula $x$ intermedia Emeric ex Loisel. uçucu yağında ana bileşen olarak linalool bulunuş olup, konvansiyonel ve organik üretimde siras1 ile oranları \%34,69 ve \%32,84 olarak ölçülmüştür. Lavandin uçucu yağında linalyl acetate oranı \%26,13-28,54 arasında değişim göstermiştir. Lavandula angıstifolia Mill. uçucu yağında ana bileşen olarak linalyl acetate belirlenmiş, konvansiyonel ve organik üretimde oranları $\% 36,28$ ve $\% 33,03$ olarak ölçülmüss, linalool oranı \%23,52-25,36 arasında bulunmuştur.

Kara ve Baydar (2011) Isparta yöresinde yetiştirilen Lavandula $x$ intermedia Emeric ex Loisel. bitkilerinin uçucu yağında linalool oranını \%46,854,6 arasinda, Garzoli ve ark. (2020) linalool oranın $(\% 35,8)$, Detar ve ark. (2020) Macaristan'da yetiştirilen iki Lavandula $x$ intermedia Emeric ex Loisel. çeşidinin linalol oranını \%41,7-58,9 arasında, Blazekovic ve ark. (2018) Hırvatistan'da yetiştirilen Lavandula $x$ intermedia Emeric ex Loisel. türünde linalool oranını $\% 57,10$ olarak tespit etmiştir. Bu türde çalışmamızdan elde ettiğimiz \%32,84-34,69 linalool oranları bu çalışmalardan elde edilen değerlerin biraz altındadır.

Rai ve ark. (2020) Lavandula angustifolia Mill. bitkisinin uçucu yağında linalyl acetate, \%20,0, Fakhari ve ark. (2005) İran'dan topladıkları Lavandula angistifolia Mill. bitkisinin uçucu yağında linalyl acetate \%13,4, Moussii ve ark. (2020) Lavandula angustifolia Mill. uçucu yağında linalyl acetate, \%9,78, Hassiotis ve ark. (2014) Yunanistan'da farklı zamanlarda hasat ettikleri Lavandula angustifolia Mill. bitkisinin uçucu yağ bileşiminde linalyl acetate, \%21,30-25,01 arasında bulmuşlardır. Seidler-Lozykowska ve ark. (2014) yaptıkları çalışmada organik olarak yetiştirilen Lavandula angustifolia Mill. uçucu yağında ana bileşen olarak linalool'ü \%42,64-60,02 arasında belirlemişlerdir. Yaptığımız çalışmada linalool oran1 \%23,52-25,36 arasında değişim göstermiştir. Bizim çalışmamızda aynı türden elde ettiğimiz linalyl acetate oranlar1 \%33,03-36,28 arasinda ölçülmüş olup, yukarıda verilen çalışmaların üzerinde gerçekleşmiştir.

Çizelge 6. Lavandin (Lavandula $x$ intermedia Emeric ex Loisel.) uçucu yağ bileşenleri (\%).

Table 6. Essential oil composition of lavandin (Lavandula $x$ intermedia Emeric ex Loisel.) (\%).

\begin{tabular}{lcccc}
\hline RI** & R.T.* & $\begin{array}{c}\text { Bileşen } \\
\text { Compounds }\end{array}$ & $\begin{array}{c}\text { Konvansiyonel (\%) } \\
\text { Conventional (\%) }\end{array}$ & $\begin{array}{c}\text { Organik (\%) } \\
\text { Organic (\%) }\end{array}$ \\
\hline 1210 & 18,112 & 1,8-cineole & 7,31 & 6,84 \\
1231 & 19,099 & beta-ocimene & 0,65 & 0,82 \\
1256 & 20,151 & 3-octanone & 0,58 & 0,45 \\
1374 & 24,934 & octen-1-ol acetate & 1,00 & 1,32 \\
1413 & 26,388 & hexyl butanoate & 0,63 & 1,02 \\
1442 & 27,402 & cis-linalool oxide & 2,65 & 3,06 \\
1471 & 28,405 & trans-linalool oxide & 2,82 & 2,08 \\
1524 & 30,181 & camphor & 4,93 & 3,25 \\
$\mathbf{1 5 4 1}$ & $\mathbf{3 0 , 7 5 2}$ & linalool & $\mathbf{3 4 , 6 9}$ & $\mathbf{3 2 , 8 4}$ \\
1553 & 31,146 & linalyl acetate & 26,13 & 28,54 \\
1603 & 32,697 & lavandulyl acetate & 9,07 & 10,62 \\
1663 & 34,459 & beta-sesquiphellandrene & 1,12 & 1,18 \\
1671 & 34,705 & lavandulol & 1,86 & 2,03 \\
1701 & 35,598 & borneol & 4,33 & 3,47 \\
1956 & 42,363 & hotrienol & 0,44 & 1,05 \\
2008 & 43,654 & caryophyllene oxide & 0,81 & 0,88 \\
\hline Toplam/Total & & 99,02 & 99,45 \\
\hline RT*: Retantion Time (Alikonma Zamani); RI** Retantion Indice (Alikonma İndisi).
\end{tabular}


Çizelge 7. Lavander (Lavandula angustifolia Mill.) uçucu yağ bileşenleri (\%).

Table 7. Essential oil composition of lavander (Lavandula angustifolia Mill.) (\%).

\begin{tabular}{ccccc}
\hline RI** & R.T.* & $\begin{array}{c}\text { Bileşen } \\
\text { Compounds }\end{array}$ & $\begin{array}{c}\text { Konvansiyonel (\%) } \\
\text { Conventional (\%) }\end{array}$ & $\begin{array}{c}\text { Organik (\%) } \\
\text { Organic (\%) }\end{array}$ \\
\hline 1063 & 12,081 & camphene & 0,68 & 0,52 \\
1210 & 18,113 & 1,8 -cineole & 2,96 & 3,02 \\
1256 & 20,155 & 3-octanone & 0,65 & 0,78 \\
1268 & 20,686 & cymene & 0,70 & 0,63 \\
1270 & 20,763 & hexyl acetate & 0,70 & 0,92 \\
1374 & 24,938 & octen-1-ol acetate & 1,66 & 1,32 \\
1442 & 27,407 & cis-linalool oxide & 4,82 & 4,12 \\
1471 & 28,413 & trans-linalool oxide & 3,55 & 3,36 \\
1524 & 30,189 & camphor & 0,68 & 0,58 \\
1541 & 30,743 & linalool & 23,52 & 25,36 \\
$\mathbf{1 5 5 3}$ & $\mathbf{3 1 , 1 5 5}$ & linalyl acetate & $\mathbf{3 6 , 2 8}$ & $\mathbf{3 3 , 0 3}$ \\
1573 & 31,755 & alpha-santalene & 0,77 & 1,05 \\
1583 & 32,069 & bornyl acetate & 0,61 & 0,96 \\
1603 & 32,703 & lavandulyl acetate & 10,34 & 11,72 \\
1663 & 34,461 & beta-sesquiphellandrene & 1,40 & 1,46 \\
1671 & 34,708 & lavandulol & 0,82 & 0,45 \\
1691 & 35,292 & cryptone & 0,65 & 1,02 \\
1701 & 35,654 & borneol & 2,31 & 2,36 \\
1956 & 42,366 & hotrienol & 1,17 & 1,08 \\
2008 & 43,652 & caryophyllene oxide & 2,46 & 3,14 \\
\hline Toplam/Total & & 96,73 & 96,88 \\
\hline RT*: Retantion Time (Alikonma Zaman1); RI** Retantion Indice (Al1konma İndisi)
\end{tabular}

Nane (Mentha spicata L., Mentha $x$ piperita L.)

Çizelge 8 ve Çizelge 9'da Mentha spicata L. ve Mentha $x$ piperita L. türlerine ait uçucu yağların bileșenleri görülmektedir. Mentha spicata L. türünde uçucu yağın ana bileşeni carvone olarak bulunmuş, konvansiyonel ve organik üretimde oranları \%59,01 ve $\% 53,54$ olarak belirlenmiştir. $\mathrm{Bu}$ türde diğer önemli bileşen olarak limonene \%14,41-15,35 arasında bulunmuştur. Mentha $x$ piperita $\mathrm{L}$. türünde ise uçucu yağın ana bileşeni olarak menthone belirlenirken, konvansiyonel ve organik uygulamada $\% 45,32$ ile $\% 40,86$ arasinda ölçülmüş, diğer ana bileșen menthol ise \%24,8226,34 arasında elde edilmiştir.

Braga ve ark. (2020) yaptıkları çalışmada Mentha spicata L. bitkisinin uçucu yağ ana bileşeni olarak carvone 75,41, Zhao ve ark. (2013) Çin'de Mentha spicata L. uçucu yağında carvone \%46,7-65,4, Kedia ve ark. (2014) yaptıkları araştırmada Hindistan'dan topladıklar1 Mentha spicata L. türünün uçucu yağında karvon \%59,60, Telci ve ark. (2010) 4 farklı lokasyonda (Aydın, Bursa,
İzmir ve Tokat) yetiştirdikleri Mentha spicata L. bitkilerinin uçucu yağında pulegon \%26,71-29,56 arasında belirlemişlerdir. Çalışmamızdan elde ettiğimiz carvone değerleri \%59,01-53,54 arasında olup, diğer çalışmalarla büyük oranda örtüşmektedir.

Özgüven ve Kırıcı (1999) 5 farklı Mentha $x$ piperita L. çeşidinde menthone oranını \%8,5062,34 arasında, Rajkumar ve ark. (2019) yaptıkları çalışmada Mentha x piperita L. uçucu yağında menton \%31,66, Almeida ve ark. (2019) Mentha x piperita L. uçucu yağında menton $\% 24,87$, Reddy ve ark. (2019) Mentha x piperita L. uçucu yağında menthone \%24,56, Smaoui ve ark. (2016) Tunus'tan topladıkları Mentha $x$ piperita L. bitkilerinde uçucu yağda menthone $\% 33,59$ olarak bulmuşlardır. Ayran ve ark. (2018) yaptıkları çalışmada Mentha x piperita $\mathrm{L}$ uçucu yağında ana bileşen olarak \%50,80 oranında menthone bulmuşlardır. Esetlili ve ark. (2015) organik olarak yetiştirilen Mentha x piperita L. uçucu yağında menthone oranının \%29,16-32,74 arasında olduğu bildirmişlerdir. Yaptığımız çalışmadan elde ettiğimiz menton değerleri $(\% 45,32-\% 40,86)$ diğer çalışmalar ile benzerlik göstermektedir. 
Çizelge 8. Nane (Mentha spicata L.) uçucu yağ bileşenleri (\%).

Table 8. Essential oil composition of spearmint (Mentha spicata L.) (\%).

\begin{tabular}{ccccc}
\hline RI** & R.T.* & $\begin{array}{c}\text { Bileşen } \\
\text { Compounds }\end{array}$ & $\begin{array}{c}\text { Konvansiyonel (\%) } \\
\text { Conventional (\%) }\end{array}$ & $\begin{array}{c}\text { Organik (\%) } \\
\text { Organic (\%) }\end{array}$ \\
\hline 1021 & 10,531 & alpha-pinene & 1,08 & 1,14 \\
1107 & 13,688 & beta-pinene & 1,29 & 1,85 \\
1208 & 14,257 & sabinene & 0,63 & 0,67 \\
1160 & 16,022 & myrcene & 2,19 & 2,65 \\
1198 & 17,647 & limonene & 14,41 & 15,35 \\
1210 & 18,113 & 1,8 -cineole & 5,36 & 5,45 \\
1334 & 23,361 & 3-octanol acetate & 0,65 & 1,05 \\
1464 & 28,159 & trans-sabinene hydrate & 1,06 & 1,32 \\
1523 & 30,157 & beta-bourbonene & 1,48 & 1,87 \\
1603 & 32,672 & beta-caryophyllene & 2,08 & 2,53 \\
1620 & 33,212 & cis-dihydro carvone & 3,72 & 2,74 \\
1638 & 33,737 & dihydro carvone & 0,44 & 1,05 \\
1663 & 34,469 & trans-beta-farnesene & 0,46 & 0,72 \\
1674 & 34,786 & dihydrocarvyl acetate & 2,24 & 3,08 \\
1719 & 36,097 & germacrene & 0,40 & 0,46 \\
1725 & 36,252 & neodihydrocarveol & 2,07 & 2,34 \\
$\mathbf{1 7 5 1}$ & $\mathbf{3 6 , 9 8 2}$ & carvone & $\mathbf{5 9 , 0 1}$ & $\mathbf{5 3 , 5 4}$ \\
1773 & 37,583 & trans-carvyl acetate & 0,56 & 0,85 \\
1985 & 43,098 & limonene dioxide & 0,38 & 0,79 \\
\hline Toplam/Total & & 99,51 & 99,45 \\
\hline RT*: Retantion Time (Alikonma Zaman1); RI** Retantion Indice (Alikonma İndisi).
\end{tabular}

Çizelge 9. Nane (Mentha x piperita L.) uçucu yağ bileșenleri (\%).

Table 9 Essential oil composition of peppermint (Mentha x piperita L.) (\%).

\begin{tabular}{lcccc} 
RI** & R.T.* & $\begin{array}{c}\text { Bileşen } \\
\text { Compounds }\end{array}$ & $\begin{array}{c}\text { Konvansiyonel (\%) } \\
\text { Conventional (\%) }\end{array}$ & $\begin{array}{c}\text { Organik (\%) } \\
\text { Organic (\%) }\end{array}$ \\
\hline 1021 & 10,531 & alpha-pinene & 0,69 & 0,78 \\
\hline 1107 & 13,697 & beta-pinene & 1,05 & 1,23 \\
1208 & 14,257 & sabinene & 0,50 & 0,54 \\
1198 & 17,645 & limonene & 1,70 & 1,84 \\
1210 & 18,107 & 1,8 -cineole & 4,55 & 5,03 \\
1464 & 28,165 & trans-sabinene hydrate & 1,72 & 1,84 \\
$\mathbf{1 4 7 3}$ & $\mathbf{2 8 , 4 8 9}$ & menthone & $\mathbf{4 5 , 3 2}$ & $\mathbf{4 0 , 8 6}$ \\
1485 & 28,903 & menthofuran & 3,85 & 4,25 \\
1565 & 31,482 & menthyl acetate & 2,99 & 3,41 \\
1595 & 32,448 & neomenthol & 1,74 & 1,62 \\
1603 & 32,688 & beta-caryophyllene & 3,52 & 4,25 \\
1642 & 33,846 & menthol & 24,82 & 26,34 \\
1659 & 34,362 & pulegone & 0,88 & 0,94 \\
1663 & 34,459 & trans-beta-farnesene & 0,47 & 0,54 \\
1699 & 35,524 & alpha-terpineol & 0,78 & 0,63 \\
1719 & 36,093 & germacrene & 2,81 & 3,02 \\
1743 & 36,751 & bicyclogermacrene & 0,31 & 0,43 \\
1746 & 36,828 & piperitone & 0,76 & 0,85 \\
2099 & 45,834 & viridiflorol & 0,55 & 0,87 \\
\hline Toplam/Total & & 99,01 & 99,27 \\
\hline$R T$
\end{tabular}

RT*: Retantion Time (Alıkonma Zamanı); RI** Retantion Indice (Alıkonma İndisi). 


\section{SONUÇ ve ÖNERILER}

$\mathrm{Bu}$ çalışmada, bazı önemli uçucu yağ bitkilerinde organik ve konvansiyonel üretim yapılan tarım alanlarından alınan bitki örneklerinin kalite özelliklerini belirlemek amaçlanmıştır. Çalışmada kullanılan materyaller, ülkemizde konvansiyonel olarak geniş alanlarda tarımı yapılan ürünler olup, son yıllarda iyi tarım ve organik tarım sertifikalı ürünlere olan talebin artması ve bu ürünlere devlet

\section{LITERATÜR LISTESİ}

Aktaş, K. 2001. Bazı Lamiaceae (Labiatae) türleri üzerinde taksonomik bir araștırma. Yüksek Lisans Tezi. Celal Bayar Üniversitesi Fen Bilimleri Enstitüsü Manisa.

Almeida, E. T. D. C., G. T. De Souza, J. P. D. S. Guedes, I. M. Barbosa, C. P. De Sousa, L. R. C. Castellano, M. Magnani, and E. L. De Souza. 2019. Mentha x piperita L. essential oil inactivates spoilage yeasts in fruit juices through the perturbation of different physiological functions in yeast cells. Food Microbiology 82:20-29.

Anonim. 2020a. Bizim Bitkiler. Erişim: https://www. bizimbitkiler.org.tr/v2/index.php.

Anonim. 2020b. Gıda Tarım ve Hayvancılık Bakanlığı Organik Tarımsal Üretim Verileri, https://www. tarimorman.gov.tr/Konular/BitkiselUretim/OrganikTarim/Istatistikler.

Anonim. 2021. Uluslararası Tarımsal Araştırma ve Eğitim Merkezi Meteoroloji Verileri, Menemen-İzmir.

Anonymous. 2010. European Pharmacopoeia (E. P.) 7th ed.; European Directorate for the Quality of Medicines\&Health Care (EDQM): Strasbourg, France, 2010, p.1231.

Arabac1, O. 1995. İzmir kekiği (Origanum onites L.)'nin yetiştirme tekniği ve kalite özellikleri üzerinde araștırma. Doktora tezi. T.C. Ege Üniversitesi Fen Bilimleri Enstitüsü Tarla Bitkileri Anabilim Dalı Bornova-İzmir.

Arabacı, O. ve E. Bayram, 2005. Aydın ekolojik koşullarında lavanta (Lavandula angustifolia mill.)'nın bazı agronomik ve kalite özellikleri üzerine bitki sıklığı ve azotlu gübrenin etkisi. A.D.Ü. Ziraat Fakültesi Dergisi 2 (2): 13-19.

Aşkun T., K. H. C. Başer, G. Tümen, and M. Kürkçüoğlu. 2010. Characterization of essential oils of some Salvia species and their antimycobacterial activities. Turkish Journal of Biology 34: 89-95.

Atalay, A. T. 2008. Konya ekolojik şartlarında yetiştirilen lavanta (Lavandula angustifolia Mill.)'da farklı dozlarda uygulanan organik ve inorganik azotlu gübrelerin verim ve kalite özellikleri üzerine etkileri. Yüksek Lisans Tezi. Selçuk Üniversitesi Fen Bilimleri Enstitüsü Tarla Bitkileri Anabilim Dalı. Konya. desteğinin olması sertifikalı üretimi teșvik etmiştir. Tibbi ve aromatik bitkilerde kalite parametreleri, en az verim değerleri kadar önemlidir. Bu nedenle, uygulanan tarım yöntemlerinin kaliteye olan etkisinin incelenmesi gerekmektedir. Yapılan çalışmada, aynı ekolojik koşullarda farklı uçucu yağ bitkilerinden organik ve konvansiyonel tarım koşullarında kalite özellikleri bakımından elde edilen değerleri ortaya konulmuştur.

Avcı, A. B. ve E. Bayram. 2013. Geliştirilmiş İzmir kekiği (Origanum onites L.) klonlarının farklı ekolojik koşullarda bazı agronomik ve teknolojik özelliklerinin belirlenmesi. Ege Üniv. Ziraat Fak. Derg. 50 (1): 13-20.

Ayran, İ., S. A. Çelik, A. Kan, and Y. Kan. 2018. A study on essential oil yield and components of dryed and fresh foliage of peppermint (Mentha piperita L.) cultivated in Turkey. International Journal of Agriculture Environment and Food Sciences 2 (1): 199- 201.

Bağcı, E. ve A. Koçak. 2008. Salvia palaestina Bentham ve Salvia tomentosa Mill. türlerinin uçucu yăg kompozisyonu, kemotaksonomik bir yaklaşım. Fırat Üniv. Fen ve Müh. Bil. Dergisi 20 (1): 35-41.

Baydar H., R. A. Marquard ve T. Karadoğan. 1999. Isparta yöresinden toplanarak ihracat edilen bazı önemli Origanum, Coridothymus, Thymbra, Salvia L. türlerinin uçucu yağ verimi ve kompozisyonu. Türkiye 3. Tarla Bitkileri Kongresi 15-18 Kasım. Adana. Cilt II, Endüstri Bitkileri, s.416-420.

Baydar, H. 2002. Isparta koşullarında İzmir kekiğinin (Origanum onites L.) verimi ve uçuçu yăg kalitesi üzerine araştırmalar. Süleyman Demirel Üniversitesi Fen Bilimleri Enstitüsü Dergisi 6 (2): 15-21.

Baydar, H. 2007. Tıbbi, Aromatik ve Keyf Bitkileri Bilimi ve Teknolojisi(Genişletilmiş II. Bask1). Süleyman Demirel Üniversitesi Ziraat Fakültesi. Yayın No: 51. Isparta.

Bayram E. 2001. Batı Anadolu florasında yetişen Anadolu adaçayı (Salvia fruticosa Mill.)'nda uygun tiplerin seleksiyonu üzerinde araştırma. Turkish Journal of Agriculture and Forestry 25: 351-357.

Bayram E., A. Ceylan ve H. Geren. 1999. Anadolu adaçay1 (Salvia fruticosa Mill.) 1slahında geliştirilen klonların agronomik ve kalite özellikleri üzerinde araştırma. Türkiye 3. Tarla Bitkileri Kongresi. Cilt II s.212-217.

Bayram, E. 1995. Geliştirilmiş İzmir kekiği (Origanum onites L.) hatlarında bazı agronomik ve kalite özelliklerinin belirlenmesi. The Journal of Agricultural Faculty of Ege Universty 32 (3): 41-48.

Bayram, E. H. Geren, A. Ceylan ve N. Özay. 1999. İzmir kekiği (Origanum onites L.)'nde farklı biçim yüksekliğinin verim ve kaliteye etkisi. Türkiye 3. Tarla Bitkileri Kongresi.15-18 Kasım. Adana. s.222-226. 
Blazekovic, B., W. Yang, Y. Wang, C. Li, M. Kindl, S. Pepeljnjak, and S. Vladimir-Knezevic. 2018. Chemical composition, antimicrobial and antioxidant activities of essential oils of Lavandula $\times$ intermedia 'Budrovka' and L. angustifolia L. cultivated in Croatia. Industrial Crops \& Products 123:173-182.

Bostancioğlu, R. B., M. Kürkçüoğlu, K. H. C. Başer, and A. T. Koparal. 2012. Assessment of anti-angiogenic and anti-tumoral potentials of Origanum onites L. essential oil. Food and Chemical Toxicology 50: 2002-2008.

Braga, V. A. A., G. D. S. Cruz, C. A. Guedes, C. T. D. S. Silva, A. A. Santos, H. N. Da Costa, C. J. C. L. Neto, A. A. C. Teixeria, and V. W. Teixeria. 2020. Effect of essential oils of Mentha spicata L. and Melaleuca alternifolia cheel on the midgut of Podisus nigrispinus (Dallas) (Hemiptera: Pentatomidae). Acta Histochemica 122 (3): 1-14.

Büyükbayraktar, A. 2014. Konya ekolojik şartlarında farklı azot dozlarında yetiştirilen Menthaxpiperita L. ve Mentha spicata L. Türlerinin kurutma yöntemlerine göre drog verimi bazı kalite özelliklerinin araştırılması. Yük. Lis. Tezi, Selçuk Ün. Fen Bil. Enst. Konya.

Ceylan, A. 1987. Tıbbi Bitkiler 2 (Uçucu Yağ İçerenler). E.Ü. Ziraat Fakültesi. Yayın No: 481. Bornova, İzmir.

Ceylan, A., A. Vömel, N. Kaya ve E. Niğdeli. 1988. İzmir kekiği (Origanum smyraeum L.)'nin adaptasyonu ve 1slahı üzerinde araştırmalar. I. Orman Tali Ürünleri Sempozyumu Programı.

Ceylan, A., E. Bayram ve H. Geren. 1999.İzmir kekiğ (Origanum onites L.) 1slahında geliştirilen klonların agronomik ve kalite özellikleri üzerinde bir araştırma. Tr. Journal of Agriculture and Forestry 23: ek say1 5.1163-1168

Ceylan, A., H. Otan, M. Polat, E. Bayram, A. O. Sarı, N. Özay, S. Kudat , N., B. Oğuz ve A. Kıtıkı. 1994. Origanum onites L. (İzmir kekiği) üzerinde agroteknik araştırmalar. T.C. Tarım ve Köyişleri Bakanlığ 1 Tarımsal Araştırmalar Genel Müdürlüğü. Ege Tarımsal Araştırma Enstitüsü. Menemen-İzmir.

Çalıkoğlu, E., M. Kıralan ve A. Bayrak. 2006. Uçucu yağ nedir, nasıl üretilir ve Türkiye'deki durumuna genel bir bakış. Türkiye 9. Gida Kongresi. Bolu. S. 1-2.

Çiçek F., M. Tutar, A. O. Sarı ve A. Bilgiç. 2011. Anadolu adaçayı (Salvia fruticosa Mill.) yapraklarında uçucu yağ oranlarının aylara göre değişimi. Türkiye 9. Tarla Bitkileri Kongresi, 12-15 Eylül. Bursa. Endüstri Bitkileri ve Biyoteknoloji. Cilt: 2, s.1287-1290.

Delamare, A. P. L., I. T. Moschen-Pistorello, L. Artico, L. Atti-Serafini, and S. Echeverrigaray. 2007. Antibacterial activity of the essential oils of Salvia officinalis L. and Salvia triloba L. cultivated in South Brazil. Food Chemistry 100: 603-608.

Demirezer, L. Ö. 2010. Bitkilerin Tipta Kullanılmas1 Konusundaki Sorumluluklarımı. Zeytinburnu/ İstanbul Bildiri Kitab1. s.87-88.
Detar, E., E. Z. Nemeth, B. Gosztola, I. Demjan, and Z. Pluhar. 2020. Effects of variety and growth year on the essential oil properties of lavender (Lavandula angustifolia Mill.) and lavandin (Lavandula $x$ intermedia Emeric ex Loisel.). Biochemical Systematics and Ecology 90: 1-7.

Economou, G., G. Panagopoulos, P. Tarantilis, D. Kalivas, V. Kotoulas, I. S. Travlos M. Polysiou, and A. Karamanos. 2011. Variability in essential oil content and composition of Origanum hirtum L., Origanum onites L., Coridothymus capitatus (L.) and Satureja thymbra L. populations from the Greek island Ikaria. Industrial Crops and Products 33: 236-241.

Erdoğan, E. A. 2014. Lamiaceae familyasina ait bazı bitkilerin uçucu yağ içeriklerinin belirlenmesi, antimikrobiyal ve antimutajenik aktivitelerinin araştırılması. Doktora Tezi. Mersin Üniversitesi Fen Bilimleri Enstitüsü Mersin.

Esetlili B. Ç., Ö. Çobanoğlu, M. Tepecik, B. Öztürk, and D. Anaç. 2015. Yield, essential nutrients and essential oils of peppermint (Mentha x piperita 1.) grown under organic farming conditions. J. of Uludag Agricultural Faculty 29 (1): 29-36.

Fakhari, A. R., P. Salehi, R. Heydari, S. N. Ebrahimi, and P. R. Haddad. 2005. Hydrodistillation-headspace solvent microextraction, a new method for analysis of the essential oil components of Lavandula angustifolia Mill. J. of Chromatography A 1098: 14-18.

Franz, C. H. 1983. Nutrient and water managment for medicinal and aromatic plants. Acta Horticulturae 132: 203-215.

Garzoli, S., S. Petralito, E. Ovidi, G. Turchetti, V. L. Masci, A. Tiezzi, J. Trilli, S. Cesa, M. A. Casadei, P. Giacomello, and P. Paolicelli. 2020. Lavandula $x$ intermedia Emeric ex Loisel. essential oil and hydrolate: Evaluation of chemical composition and antibacterial activity before and after formulation in nanoemulsion. Industrial Crops \& Products 145: 1-9.

Hassiotis, C. N., F. Ntana, D. M. Lazari, S. Poulios, and K. E. Vlachonasios. 2014. Environmental and developmental factors affect essential oil production and quality of Lavandula angustifolia Mill. during flowering period. Ind. Crops and Products 62: 359-366.

İlter, E. ve A. Altındişli. 1996. "Ekolojik Tarım”, Ekolojik Tarım ve İlkeleri, (Ed. Ekolojik Tarım Organizasyonu Derneği), Emre Basımevi. İzmir, s.1.

İlter, E., U. Aksoy ve A. Altındişli. 2012. Ekolojik Tarımın Tarihçesi ve Gelişimi, (Ed. Ekolojik Tarım Organizasyonu Derneği), İmak Ofset. Ankara.

Kahraman, A., and M. Doğan. 2010. Comparative study of Salvia limbata C.A. and S. palaestina Bentham (sect. Aethiopis Bentham, Labiatae) from East Anatolia, Turkey. Acta Bot Croat 69: 47-64.

Kalafatcılar, Ö. A. 1996. Uçucu yağ bitkileri ekotiplerinin bazı morfolojik, anatomik ve kalite kriterleri üzerinde araştırma. Doktora Tezi. Ege Üniversitesi, Fen Bilimleri Enstitüsü, Tarla Bitkileri Ana Bilim Dalı Bornova-İzmir 
Kara, N. 2011. Uçucu yağ üretimine uygun lavanta (lavandula sp.) çeşitlerinin belirlenmesi ve mikroçoğaltım olanaklarının araştırılması. Doktora Tezi. Süleyman Demirel Üniversitesi Fen Bilimleri Enstitüsü Tarla Bitkileri A.B.D. Isparta.

Kara, N. ve H. Baydar. 2011. Türkiye'de lavanta üretim merkezi olan isparta ili kuyucak yöresi lavantalarının (Lavandula $x$ intermedia Emeric ex Loisel.) uçucu yağ özellikleri. Selçuk Tarım ve Gıda Bilimleri Dergisi 25 (4): $42-46$

Karayel, H. B. ve M. Akçura. 2016. Farklı lokasyonlarda yetiştirilen Anadolu adaçayı (Salvia fruticosa Mill.)'in uçucu yağ bileşenlerindeki değişimlerin incelenmesi. Gaziosmanpaşa Bilimsel Araştırma Dergisi 13: 13-23.

Karık, Ü. 2015. Ege ve Batı Akdeniz Florasındaki Anadolu adaçayı (Salvia fruticosa Mill.) populasyonlarının bazı verim ve kalite özellikleri. Tekirdağ Ziraat Fakültesi Dergisi 12 (2): 32-42.

Karoussou R., and S. Kokkini 1997. Distrubition and clinal varitian of Salvia fruticosa Mill. (Labiateae) on the Island of Crete (Greece). Willdenowia 27: 113-117

Kedia, A., B. Prakash, P. K. Mishra, C. S. Chanotiya, and N. K. Dubey. 2014. Antifungal, antiaflatoxigenic, and insecticidal efficacy of spearmint (Mentha spicata L.) essential oil. International Biodeterioration \& Biodegradation 89: 29-36.

Kırman, H. 1993. Geliştirilmiş izmir kekiği (Origanum onites L.) hatlarının bazı agronomik ve kalite özelliklerinin belirlenmesi üzerinde araştırma. Yüksek Lisans Tezi. Ege Üniversitesi Fen Bilimleri Enstitüsü Tarla Bitkileri Anabilim Dalı Bornova-İzmir.

Kıtıkı, A. A. O. Sarı, B. Oğuz, A. Ceylan, E. Bayra ve N. Özay. 1997. Batı Anadolu İzmir kekiği (Origanum onites L.) populasyonlarında bazı özellikler açısından üstün tiplerin belirlenmesi ve kültür koşullarında performanslarının saptanması. T.C. Tarım ve Köyişleri Bakanlığı Tarımsal Araştırmalar Genel Müdürlüğü. Ege Tarımsal Araştırma Enstitüsü. Menemen-İzmir.

Kocabaş F. I., M. Kaplan M. Kürkçüoğlu, and K. H. C. Başer. 2010. Effects of different organic manure applications on the essential oil components of Turkish sage (Salvia fruticosa Mill.). Asian Journal of Chemistry 22 (2): 1599-1605.

Kosakowska, O., and K. Bqczek. 2019. Yield and quality of "Greek oregano" (Origanum vulgare subsp. hirtum) herb from organic production system in temperate climate. Industrial Crops and Products 141 (1) doi.org/10.1016/j.indcrop.2019.111782.

Leontaritou, P., F. N. Lamari, V. Papasotiropoulos, and G. Iatrou. 2020. Morphological, genetic and essential oil variation of Greek sage (Salvia fruticosa Mill.) populations from Greece. Industrial Crops \& Products 150: $1-15$.
Mossi A. J., R. L. Cansian, N. Paroul, G. Toniazzo, J. V. Oliveira, M. K. Pierozan, G. Pauletti, L. Rota, A. C. Santos, and L. A. Serafini. 2011. Morphological characterisation and agronomical parameters of different species of Salvia L. sp. (Lamiaceae). Brazilian Journal of Biology 71 (1): 121-129.

Moussii, I. M., K. Nayme, M. Timinouni, J. Jamaleddine, H. Filali, and F. Hakkou. 2020. Synergistic antibacterial effects of Moroccan Artemisia herba alba, Lavandula angustifolia Mill. and Rosmarinus officinalis L. essential oils. Synergy 10: 1-7.

Otan, H., A. O. Sarı, A. Ceylan, E. Bayram, N. Özay ve N. Kaya. 1994. Batı Anadolu florasında yayılış gösteren Origanum onites L. (İzmir kekiği) populasyonlarında bazı kalite özellikleri. Tarla Bitkileri Kongresi. 25-29 Nisan. İzmir. 146-149.

Özgüven, M. ve S. Kırıc1, 1999. Farklı ekolojilerde nane (Mentha) türlerinin verim ile uçucu yağ oran ve bileşenlerinin araştırılması. Tr. J. of Agriculture and Forestry 23: 465-472.

Özkan, A., and E. Erdoğan. 2011. A comparative evaluation of antioxidant and anticancer activity of essential oil from Origanum onites L. (Lamiaceae) and its two major phenolic components. Turk J Biol 35: 735-742.

Özsoy, Ü. 1995. Muğla yöresinden toplanan izmir kekiği (Origanum onites L.) populasyonlarının bazı agronomik ve kalite özellikleri üzerine araştırmalar. Yüksek Lisans Tezi. Ege Üniversitesi Fen Bilimleri Enstitüsü Tarla Bitkileri Anabilim Dalı Bornovaİzmir.

Palevitch, D. 1987. Recent advances in the cultivation of medicinal and aromatic plants. Acta Horticulturae 208: p.29-35.

Putievsky, E., U. Ravid, and N. Dudai. 1986. The essential oil and yield components from various plant parts of Salvia fruticosa Mill. Journal of Natural Products 49: 1015-1017.

Rai, V. K., P. Sinha, K. S. Yadav, A. Shukla, A. Saxena, D. U. Bawankule, S. Tandon, F. Khan, C. S. Chanotiya, and N. P. Yadav. 2020. Anti-psoriatic effect of Lavandula angustifolia Mill. essential oil and its major components linalool and linalyl acetate. Journal of Ethnopharmacology 261.

Rajkumar, V., C. Gunasekaran, I. K. Christy, J. Dharmaraj, P. Chinnaraj, and C. A. Paul. 2019. Toxicity, antifeedant and biochemical efficacy of Mentha $x$ piperita L. essential oil and their major constituents against stored grain pest. Pesticide Biochemistry and Physiology 156: $138-144$.

Reddy, D. N., A. J. Al-Rajab, M. Sharma, M. M. Moses, G. R. Reddy, and M. Albratty. 2019. Chemical constituents, in vitro antibacterial and antifungal activity of Mentha $x$ piperita L. (peppermint) essential oils. J. of King Saud University 31: 528-533. 
Renaud, E. N. C., D. J. Charles, and J. E. Simon. 2001. Essential oil quantity and composition from 10 cultivars of organically grown lavender and lavandin. J. of Essential Oil Res. 13 (4): 269-273.

Seidler-Lozykowska K, Mordalski R, Kucharski W B. Kċdzia, and J. Bocianowski. 2014. Yielding and quality of lavender flowers (Lavandula angustifolia Mill.) from organic cultivation. Acta Sci. Pol., Hortorum Cultus 13 (6): 173-183.

Seidler-Lozykowska, K., J. Bocianowski, and E. Karpinska. 2014. Yield and quality of sage herb (Salvia officinalis L.) from organic cultivation. Bioligical Agriculture and Horticulture 31 (1) doi.org/10.1080/01448765. 2014.966323.

Skoula, M., J. E. Abbes, and C. B. Johnson. 2000. Genetic variation of volatiles and rosmarinic acid in populations of Salvia fruticosa Mill. growing in Crete. Biochemical Systematics and Ecology 28: 555-561.

Smaoui, S., A. B. Hsouna, A. Lahmar, K. Ennouri, A. MtibaaChakchouk, I. Sellem, S. Najah, M. Bouaziz, and L. Mellouli. 2016. Bio-preservative effect of the essential oil of the endemic Mentha x piperita L. used alone and in combination with BacTN635 in stored minced beef meat. Meat Science 117: 196-204.

Sönmez, Ç. ve H. Okkaoğlu. 2019. The effect of diurnal variation on some yield and quality characteristics of lavender (Lavandula angustifolia Mill.) under Çukurova ecological conditions. Turkish Journal of Agriculture - Food Science and Technology 7 (3): 531-535.

Stefanaki, A., C. M. Cook, T. Lanaras, and S. Kokkini. 2016. The Oregano plants of Chios Island (Greece): Essential oils of Origanum onites L. growing wild in different habitats. Industrial Crops and Products 82: 107-113.

Sülü, E. 2010. Seçilmiş Nane (Mentha spp.) klonlarının Tokat şartlarında verim ve kalite özelliklerinin belirlenmesi. Yüksek Lisans Tezi. Gaziosmanpaşa Üniversitesi Fen Bilimleri Enstitüsü Tokat.
Telci, İ. 2001. Farklı Nane (Mentha spp.) klonlarının bazı morfolojik, tarımsal ve teknolojik özelliklerinin belirlenmesi üzerinde bir araştırma. Doktora Tezi, Gaziosmanpaşa Üniversitesi Fen Bilimleri Enstitüsü Tokat.

Telci, I., I. Demirtas, E. Bayram, O. Arabaci, and O. Kacar. 2010. Environmental variation on aroma components of pulegone/piperitone rich spearmint (Mentha spicata L.). Industrial Crops and Products 32: 588-592.

Tuğay, M. E., N. Kaya, G. Yılmaz, I. Telci ve E. Dönmez. 2000. TUBITAK, Togtag-1690 Nolu Proje Kesin Sonuç Raporu, Tokat ve Çevresinde Yaygın Olarak Bulunan Bazı Aromatik Bitkilerin Bitkisel ve Teknolojik Özellikleri.

Ulcay, S., ve G. Şenel. 2018. Lamiaceae familyasına ait Lycopus europaeus L. türü üzerinde anatomik bir araştırma. Sinop Üniversitesi Fen Bilimleri Dergisi 3 (1): 45-52.

Yaniv, Z., A. Dafni, and D. Palcvitch. 1982. Labiateae as medicinal plants in Israel. In: Martinus Nijhoff Publishers, The Hague p. 265-269.

Yaşar, S. 2005. Çukurova Üniversitesi kampüsünde doğal olarak yetişen bazı çok yıllık tıbbi bitkilerin toprak özellikleri ile sabit ve uçucu yağ içeriklerinin belirlenmesi. Yüksek Lisans Tezi. Çukurova Üniversitesi Fen Bilimleri Enstitüsü. Adana.

Zhao, D., Y. W. Xu, G. L. Yang, A. M. Husaini, and W. Wu. 2013. Variation of essential oil of Mentha haplocalyx Briq. and Mentha spicata L. from China. Industrial Crops and Products 42: 251-260. 